\title{
Biophysical Model of AMPA Receptor Trafficking and Its Regulation during Long-Term Potentiation/ Long-Term Depression
}

\author{
Berton A. Earnshaw and Paul C. Bressloff \\ Department of Mathematics, University of Utah, Salt Lake City, Utah 84112
}

\begin{abstract}
AMPA receptors mediate the majority of fast excitatory synaptic transmission in the CNS, and evidence suggests that AMPA receptor trafficking regulates synaptic strength, a phenomenon implicated in learning and memory. There are two major mechanisms of AMPA receptor trafficking: exocytic/endocytic exchange of surface receptors with intracellular receptor pools, and the lateral diffusion or hopping of surface receptors between the postsynaptic density and the surrounding extrasynaptic membrane. In this paper, we present a biophysical model of these trafficking mechanisms under basal conditions and during the expression of long-term potentiation (LTP) and depression (LTD). We show how our model reproduces a wide range of physiological data, and use this to make predictions regarding possible targets of second-messenger pathways activated during the induction phase of LTP/LTD.
\end{abstract}

Key words: AMPA receptor trafficking; long-term potentiation; long-term depression; synaptic plasticity; exocytosis/endocytosis; membrane diffusion

\section{Introduction}

AMPA receptors mediate the majority of fast excitatory synaptic transmission in the CNS. These ionotropic glutamate receptors are highly clustered at the postsynaptic density (PSD) of a synapse, which is the protein-rich domain in the postsynaptic membrane that is directly apposed to the presynaptic active zone. Receptors are localized within the PSD through interactions with various scaffolding proteins and cytoskeletal elements. There is a large body of experimental evidence suggesting that fast trafficking of AMPA receptors into and out of the PSD contributes to activity-dependent long-lasting changes in synaptic strength (Malinow and Malenka, 2002; Sheng and Kim, 2002; Song and Huganir, 2002; Bredt and Nicoll, 2003; Choquet and Triller, 2003; Triller and Choquet, 2003, 2005; Collingridge et al., 2004; Kennedy and Ehlers, 2006). Such changes are thought to be a necessary subcellular component of certain forms of learning and memory (Bliss and Collingridge, 1993; Malenka and Nicoll, 1999). AMPA receptor trafficking appears to occur through a combination of two major mechanisms: exocytic/endocytic exchange of surface receptors with intracellular receptor pools, and lateral diffusion of receptors between the PSD and the surrounding extrasynaptic membrane (ESM). It follows that, under basal conditions, the steady-state receptor concentration within a synapse is determined by a dynamical equilibrium in which the various receptor fluxes into and out of the PSD are balanced. Activity-dependent changes of one or more of these fluxes can

Received June 13, 2006; revised Sept. 21, 2006; accepted 0ct. 19, 2006

This work was supported by the National Science Foundation (DMS 0515725 and RTG 0354259).

Correspondence should be addressed to Paul C. Bressloff at the above address. E-mail: bressloff@math.utah.edu DOI:10.1523/JNEUROSCI.3601-06.2006

Copyright $\odot 2006$ Society for Neuroscience $\quad$ 0270-6474/06/2612362-12\$15.00/0 then modify the number of receptors in the PSD and thus alter the strength of a synapse.

The precise mechanisms underlying the activity-dependent regulation of AMPA receptor trafficking are currently not known. However, they are likely to involve one or more of the following processes: changes in the interaction between receptors and scaffolding proteins within the PSD, changes in the rates of exocytosis/endocytosis, and modifications in membrane or receptor structure that alter the surface transport of receptors. In this paper, we present a mathematical model of receptor trafficking that takes into account all of these processes. The dendritic spine is partitioned into two compartments, one corresponding to the PSD and the other to the ESM. Diffusion of free receptors within each compartment is assumed to be sufficiently fast so that the corresponding receptor concentrations can be treated as spatially uniform. Our model thus consists of a system of ordinary differential equations that determines the temporal dynamics of the synaptic and extrasynaptic receptor concentrations. We analyze these equations to determine the steady-state receptor concentration under basal conditions, and to investigate the time course of variations in receptor number induced by modifications in one or more model parameters. We show how our model can generate changes in synaptic strength that are consistent with those found in the most studied forms of synaptic plasticity, namely, NMDA receptor-mediated long-term potentiation (LTP) (Bliss and Lomo, 1973) and long-term depression (LTD) (Dudek and Bear, 1992, 1993). This allows us to identify possible targets of second-messenger pathways that are activated during the induction phase of LTP/LTD.

\section{Materials and Methods}

Two-compartment model of a dendritic spine. To investigate the role of AMPA receptor trafficking in synaptic plasticity, we construct a simpli- 
fied two-compartment model of the surface membrane of a dendritic spine (see Fig. 1A). The first compartment represents the PSD region of the spine head and the second compartment represents the ESM of the remaining spine head and neck. We assume that AMPA receptors diffuse freely in the extrasynaptic membrane. Within the PSD, however, AMPA receptor diffusion proceeds in a highly obstructed manner. This is probably attributable to a number of factors including the attraction and binding of receptors to scaffolding proteins, the transient corralling of receptors to restricted domains by the underlying actin cytoskeleton, and the repulsion of receptors by picket-like transmembrane proteins. Single-particle tracking data suggest that the PSD acts as a confinement domain for diffusing receptors, and that about one-half of the AMPA receptors within the PSD are mobile (Choquet and Triller, 2003; Groc et al., 2004; Triller and Choquet, 2005; Ashby et al., 2006).

To model the confinement of diffusing particles within the PSD, we treat the boundary between the PSD and ESM compartments as a potential barrier over which receptors must hop to enter or exit the PSD. For simplicity, the net flux across the boundary is taken to be proportional to the difference in concentrations on either side of the barrier, with the hopping rate dependent on the barrier height. An alternative model of confinement is to assume that the boundary between the PSD and ESM is impermeable except for small openings within the boundary through which receptors can diffuse (Holcman and Schuss, 2004). Receptors can also diffuse between the ESM and the surrounding membrane of the dendritic cable, with the net flux dependent on the geometry of the spine neck and the background concentration of receptors within the dendritic membrane. Indeed, it has recently been shown experimentally that there is a barrier to diffusion at the spine neck, and thus changes in spine morphology could provide a mechanism for regulating receptor trafficking (Ashby et al., 2006). We model the effects of this barrier by assuming that receptors hop between the ESM and dendrite at a rate that depends on spine geometry.

In addition to the lateral movement of AMPA receptors within the plasma membrane, there is a continual exchange of surface receptors with pools of intracellular receptors through exocytosis/endocytosis (Luscher et al., 1999; Ehlers, 2000; Passafaro et al., 2001; Blanpied et al., 2002; Song and Huganir, 2002; Park et al., 2004). In fact, there are at least two separate sources of intracellular AMPA receptors, one consisting of glutamate receptor $1 / 2(\mathrm{GluR} 1 / 2)$ heteromers that are inserted into the ESM and the other consisting of GluR2/3 heteromers that are inserted into the PSD during constitutive recycling. Because the expression of LTP and LTD is thought to involve changes in the trafficking of GluR1/2 and GluR2/3, respectively, it is important to distinguish explicitly between these two receptor types. We further assume that both receptor types undergo endocytosis from the ESM, and that there is no receptor endocytosis directly from the PSD (Blanpied et al., 2002). The latter is consistent with the emerging picture that, during constitutive recycling, receptors diffuse from the PSD to the ESM, are endocytosed, and either sorted to lysomes for degradation or reinserted into the PSD (Ehlers, 2000). Passafaro et al. (2001) find that, under basal conditions, the rate of receptor insertion into the PSD is quantitatively similar to the rate of endocytosis, both having a time constant of $\sim 10 \mathrm{~min}$. This is also consistent with changes in receptor number in response to blocking exocytosis/endocytosis (Luscher et al., 1999). They also find that the basal rate of exocytosis to the ESM is slower, having a time constant of at least 30 min. Note, however, that more recent data by Adesnik et al. (2005) suggest that constitutive recycling may take hours rather than minutes, and occur through exocytosis at the cell body followed by lateral membrane diffusion, rather than via direct insertion into dendritic spines. However, it is currently not clear how to reconcile these results with previous studies.

We assume that within the PSD each receptor type exists in one of two states, either bound to a scaffolding protein or free (unbound), whereas in the ESM all receptors are taken to be free. We also assume that, under basal conditions, there is a fixed concentration $L$ of binding sites within the PSD, which are taken to be nonspecific with respect to receptor type. There is experimental evidence to suggest that in mature synapses the trafficking of scaffolding proteins such as PSD-95, which play a major role in anchoring glutamate receptors to the PSD, is much slower than the fast trafficking of AMPA receptors, with the former taking place over a period of hours rather than minutes (Okabe et al., 1999; Inoue and Okabe, 2003). Thus, to a first approximation, we can neglect the dynamics of $L$ associated with the turnover of scaffolding proteins. However, when considering changes in AMPA receptor trafficking during LTP/ LTD, we will assume that there is an associated trafficking of "slot proteins" (Shi et al., 2001; Malinow, 2003) to or from the PSD that will be modeled in terms of a dynamical equation for $L$ (see Results).

Model equations. Experimental estimates for the diffusivity of mobile receptors in the PSD and ESM are of the order $D=0.01$ and $D=0.1 \mu \mathrm{m}^{2}$ $\mathrm{s}^{-1}$, respectively (Borgdorff and Choquet, 2002; Groc et al., 2004; Adesnik et al., 2005; Ashby et al., 2006). Given that the typical length scales of the PSD and ESM are $l=0.1 \mu \mathrm{m}$ and $l=1 \mu \mathrm{m}$ (Sorra and Harris, 2000), it follows that the time-scale $l^{2} / D$ for diffusion within each compartment is $1-10 \mathrm{~s}$, which is faster than other components of AMPA receptor trafficking such as exocytosis/endocytosis as well as the time course for LTP/LTD. Hence, by treating each compartment as spatially homogeneous, we can take the corresponding receptor concentrations to be spatially uniform and thus neglect the effects of intracompartmental diffusion (see Discussion). It follows that the temporal variation in receptor concentrations can be represented in terms of a system of ordinary differential equations that describe the following processes: the firstorder kinetics associated with binding/unbinding to scaffolding proteins within the PSD, the exocytosis of GluR1/2 receptors into the ESM and GluR2/3 receptors into the PSD, the endocytosis of both classes of receptor from the ESM, the hopping of free receptors between the PSD and ESM, and the hopping of free receptors between the ESM and external dendritic cable. These processes and their associated transition rates are summarized in Figure $1 B$.

For ease of notation, we denote GluR1/2 heteromers as type I and GluR2/3 heteromers as type II. For each receptor type $j, j=\mathrm{I}$, II, let $P_{j}$ and $Q_{j}$ denote, respectively, the free and bound receptor concentrations in the PSD, and let $R_{j}$ represent the corresponding free receptor concentration in the ESM. We take the PSD to be a disc of radius $r=0.2 \mu \mathrm{m}$ (Sorra and Harris, 2000) and surface area $A_{\mathrm{PSD}}=\pi r^{2}$, and take the ESM to have a surface area $A_{\mathrm{ESM}}=10 A_{\mathrm{PSD}}$. The dynamics of the free receptor concentrations in the PSD is described in terms of the following kinetic equations:

$$
\begin{gathered}
\frac{d P_{\mathrm{I}}}{d t}=-\alpha_{\mathrm{I}}\left(L-Q_{\mathrm{I}}-Q_{\mathrm{II}}\right) P_{\mathrm{I}}+\beta_{\mathrm{I}} Q_{\mathrm{I}}-\frac{h_{\mathrm{I}}}{A_{\mathrm{PSD}}}\left(P_{\mathrm{I}}-R_{\mathrm{I}}\right) \\
\frac{d P_{\mathrm{II}}}{d t}=-\alpha_{\mathrm{II}}\left(L-Q_{\mathrm{I}}-Q_{\mathrm{II}}\right) P_{\mathrm{II}}+\beta_{\mathrm{II}} Q_{\mathrm{II}}-\frac{h_{\mathrm{II}}}{A_{\mathrm{PSD}}}\left(P_{\mathrm{II}}-R_{\mathrm{II}}\right)+\frac{\sigma_{\mathrm{II}}}{A_{\mathrm{PSD}}},
\end{gathered}
$$

and the corresponding bound receptor concentrations satisfy the following equations:

$$
\begin{gathered}
\frac{d Q_{\mathrm{I}}}{d t}=\alpha_{\mathrm{I}}\left(L-Q_{\mathrm{I}}-Q_{\mathrm{II}}\right) P_{\mathrm{I}}-\beta_{\mathrm{I}} Q_{\mathrm{I}} \\
\frac{d Q_{\mathrm{II}}}{d t}=\alpha_{\mathrm{II}}\left(L-Q_{\mathrm{I}}-Q_{\mathrm{II}}\right) P_{\mathrm{II}}-\beta_{\mathrm{II}} Q_{\mathrm{II}} .
\end{gathered}
$$

The first two terms on the right-hand side of Equations 1a and 1b, and 2a and $2 \mathrm{~b}$, represent the first-order kinetics for the binding and unbinding of receptors to scaffolding proteins, with $L-Q_{I}-Q_{\text {II }}$ specifying the concentration of free binding sites. The rates of binding and unbinding are denoted by $\alpha_{j}, \beta_{j}$ for $j=\mathrm{I}$, II. The third term on the right-hand side of Equations $1 \mathrm{a}$ and $\mathrm{lb}$ represents the flux of receptors from the PSD to the ESM with associated hopping rate $h_{j}, j=\mathrm{I}$, II. Type II receptors also undergo exocytosis within the PSD at an insertion rate $\sigma_{\text {II }}$ (last term in Equation $1 \mathrm{~b})$. The rate of exocytosis satisfies $\sigma_{\mathrm{II}}=\kappa_{\mathrm{II}}(1-f) S_{\mathrm{II}}$, where $S_{\mathrm{II}}$ is the number of type II receptors in the intracellular store, $(1-f)$ is the fraction of intracellular receptors recycled to the surface (rather than degraded), and $\kappa_{\mathrm{II}}$ is the insertion rate per receptor. For simplicity, we absorb the factor $1-f$ into $\kappa_{\mathrm{II}}$. We assume that the intracellular pool of GluR2/3 receptors is sufficiently large and the rate of receptor insertion is 
sufficiently slow so that the depletion of the pool because of exocytosis can be neglected, that is, $\sigma_{\mathrm{II}}$ can be treated as a constant.

The receptor concentrations in the ESM evolve according to the following kinetic equations:

$$
\begin{gathered}
\frac{d R_{\mathrm{I}}}{d t}=\frac{h_{\mathrm{I}}}{A_{\mathrm{ESM}}}\left(P_{\mathrm{I}}-R_{\mathrm{I}}\right)-\frac{\Omega_{\mathrm{I}}}{A_{\mathrm{ESM}}}\left(R_{\mathrm{I}}-\bar{R}_{\mathrm{I}}\right)-k_{\mathrm{I}} R_{\mathrm{I}}+\frac{\sigma_{\mathrm{I}}}{A_{\mathrm{ESM}}} \\
\frac{d R_{\mathrm{II}}}{d t}=\frac{h_{\mathrm{II}}}{A_{\mathrm{ESM}}}\left(P_{\mathrm{II}}-R_{\mathrm{II}}\right)-\frac{\Omega_{\mathrm{II}}}{A_{\mathrm{ESM}}}\left(R_{\mathrm{II}}-\bar{R}_{\mathrm{II}}\right)-k_{\mathrm{II}} R_{\mathrm{II}} .
\end{gathered}
$$

The first term on the right-hand side of Equations $3 \mathrm{a}$ and $3 \mathrm{~b}$ represents the flux of receptors from the PSD to the ESM, and the second term is the corresponding flux from the ESM to the surrounding dendrite. The latter flux is taken to be proportional to the difference between the free receptor concentration $R_{j}$ and a fixed background receptor concentration within the dendrite, which is denoted by $\bar{R}_{j}, j=\mathrm{I}$, II. The third term on the right-hand side of Equations $3 \mathrm{a}$ and $3 \mathrm{~b}$ represents endocytosis at a rate $k_{j}$. Finally, type I receptors also undergo exocytosis at a rate $\sigma_{\mathrm{I}}$ (last term in Equation 3a), with $\sigma_{\mathrm{I}}=\kappa_{\mathrm{I}} S_{\mathrm{I}}$, where $S_{\mathrm{I}}$ is the number of type I receptors in the associated intracellular store and $\kappa_{\mathrm{I}}$ is the insertion rate per receptor. $S_{\mathrm{I}}$ evolves according to the following first-order equation:

$$
\frac{d S_{\mathrm{I}}}{d t}=-\kappa_{\mathrm{I}} S_{\mathrm{I}}+\delta_{\mathrm{I}}
$$

where $\delta_{\mathrm{I}}$ is the net rate of receptor synthesis. In steady state, we have $\sigma_{\mathrm{I}}=$ $\delta_{\mathrm{I}}$. However, during LTP, the rapid insertion of GluR1/2 into the ESM through exocytosis will significantly deplete the corresponding intracellular pool so that $\sigma_{\mathrm{I}}$ cannot be treated as time independent (see Results).

Steady-state solution. For fixed parameter values, there is a unique steady-state solution, which is obtained by setting the right-hand sides of Equations 1-4 to zero. First, Equation 2 implies that, in the steady state, the free and bound receptor concentrations within the PSD are related according to the following:

$$
Q_{\mathrm{I}}=\frac{\rho_{\mathrm{I}}}{1+\rho_{\mathrm{I}}+\rho_{\mathrm{II}}} L, Q_{\mathrm{II}}=\frac{\rho_{\mathrm{II}}}{1+\rho_{\mathrm{I}}+\rho_{\mathrm{II}}} L,
$$

where

$$
\rho_{\mathrm{I}}=\frac{\alpha_{\mathrm{I}} P_{\mathrm{I}}}{\beta_{\mathrm{I}}}, \rho_{\mathrm{II}}=\frac{\alpha_{\mathrm{II}} P_{\mathrm{II}}}{\beta_{\mathrm{II}}} .
$$

Equations 1 and 3 then imply that

$$
P_{\mathrm{I}}=R_{\mathrm{I}}, P_{\mathrm{II}}=R_{\mathrm{II}}+\frac{\sigma_{\mathrm{II}}}{h_{\mathrm{II}}}
$$

with

$$
R_{\mathrm{I}}=\frac{\sigma_{\mathrm{I}}+\Omega_{\mathrm{I}} \bar{R}_{\mathrm{I}}}{k_{\mathrm{I}} A_{\mathrm{ESM}}+\Omega_{\mathrm{I}}}, R_{\mathrm{II}}=\frac{\sigma_{\mathrm{II}}+\Omega_{\mathrm{II}} \bar{R}_{\mathrm{II}}}{k_{\mathrm{II}} A_{\mathrm{ESM}}+\Omega_{\mathrm{II}}} .
$$

Given the steady-state receptor concentrations, the total number of AMPA receptors in the PSD is $N=N_{\mathrm{I}}+N_{\mathrm{II}}$ with $N_{j}=\left(P_{j}+Q_{j}\right) A_{\mathrm{PSD}}$. If we assume that the strength of the synapse is proportional to the total number of synaptic receptors $N$, then we can determine how the steadystate synaptic strength depends on the various parameters of the model (see Results).

A number of qualitative features of the steady-state receptor concentrations can be immediately deduced from Equations 5-8. First, Equations 5 and 6 imply that, in the regime where the rate of binding is sufficiently large relative to the rate of unbinding, that is, $\alpha_{j} / P_{j} \gg \beta_{j}$, almost all the binding sites are occupied and $Q_{\mathrm{I}}+Q_{\mathrm{II}} \approx L$. On the other hand, if $\alpha_{j} / P_{j} \ll \beta_{j}$, then the binding sites are unsaturated and the number of bound receptors varies linearly with the number of unbound receptors according to $Q_{j} \approx \rho_{j} L$. Second, Equation 7 shows that to maintain a larger concentration of free GluR2/3 receptors in the PSD compared with the ESM (Nusser et al., 1998), the hopping parameter $h_{\mathrm{II}}$ must be sufficiently small. In other words, there needs to be some form of barrier to diffusion between the PSD and ESM. Finally, Equation 8 implies that if receptors hop freely between the ESM and surrounding dendritic membrane (large $\Omega_{j}$ ), then the receptor concentration in the ESM is approximately equal to the background concentration,

$$
R_{j} \approx \bar{R}_{j}
$$

It then follows from Equation 7 that the receptor concentrations within the PSD are independent of the rates of endocytosis $k_{j}$ (as well as the rate of exocytosis $\sigma_{\mathrm{I}}$ ), which contradicts the experimental results of Luscher et al. (1999). Therefore, there should also be an effective barrier to diffusion between the ESM and dendritic membrane, as recently observed experimentally by Ashby et al. (2006).

Model of LTD. We briefly describe the extension of our model used in the study of LTD (see Results). Both free and bound GluR2/3 receptors in the PSD are now assumed to be in two distinct phosphorylation states, which are labeled by $a$ and $b$. [These correspond to association with the proteins glutamate receptor-interacting protein (GRIP)/AMPA receptor-binding protein $(\mathrm{ABP})$ and protein interacting with $\mathrm{C}$ kinase 1 (PICK1), respectively (see Fig. $1 C$ and Results).] Receptors in the $a$ state behave as in the previous model, whereas those in the $b$ state are assumed to have a faster unbinding rate $\beta_{\mathrm{II}}{ }^{*}$, zero binding rate $\left(\alpha_{\mathrm{II}}{ }^{*}=0\right)$, and a faster rate $h_{\mathrm{II}}{ }^{*}$ of hopping to the ESM. Decomposing the free and bound GluR2/3 receptor concentrations according to $P_{\mathrm{II}}=P_{\mathrm{II}, a}+P_{\mathrm{II}, b}$ and $Q_{\mathrm{II}}=Q_{\mathrm{II}, a}+Q_{\mathrm{II}, b}$, we have the following modified system of equations for the dynamics of GluR2/3 receptor concentrations within the PSD:

$$
\begin{gathered}
\frac{d P_{\mathrm{II}, a}}{d t}=-\alpha_{\mathrm{II}}\left(L-Q_{\mathrm{I}}-Q_{\mathrm{II}}\right) P_{\mathrm{II}, a}+\beta_{\mathrm{II}} Q_{\mathrm{II}, a}-\frac{h_{\mathrm{II}}}{A_{\mathrm{PSD}}}\left(P_{\mathrm{II}, a}-R_{\mathrm{II}}\right)+ \\
\frac{\sigma_{\mathrm{II}}}{A_{\mathrm{PSD}}}+\nu P_{\mathrm{II}, b}-\mu P_{\mathrm{II}, a} \\
\frac{d P_{\mathrm{II}, b}}{d t}=\beta_{\mathrm{II}}^{\star} Q_{\mathrm{II}, b}-\frac{h_{\mathrm{II}}^{*}}{A_{\mathrm{PSD}}} P_{\mathrm{II}, b}-\nu P_{\mathrm{II}, b}+\mu P_{\mathrm{II}, a}
\end{gathered}
$$

and

$$
\frac{d Q_{\mathrm{II}, a}}{d t}=\alpha_{\mathrm{II}}\left(L-Q_{\mathrm{I}}-Q_{\mathrm{II}}\right) P_{\mathrm{II}, a}-\beta_{\mathrm{II}} Q_{\mathrm{II}, a}+\nu Q_{\mathrm{II}, b}-\mu Q_{\mathrm{II}, a}
$$

$$
\frac{d Q_{\mathrm{II}, b}}{d t}=-\beta_{\mathrm{II}}^{\star} Q_{\mathrm{II}, b}-\nu Q_{\mathrm{II}, b}+\mu Q_{\mathrm{II}, a} .
$$

Here, $\mu, \nu$ denote the transition rates between the $a$ and $b$ states, which for simplicity are taken to be the same for free and bound receptors. We assume that, within the ESM, receptors in the $b$ state are rapidly endocytosed so that $R_{\mathrm{II}}=R_{\mathrm{II}, a}$ and the dynamics for $R_{\mathrm{II}}$ is the same as in the previous model (Eq. 3b). The GluR1/2 dynamics is also unaltered.

\section{Results}

We analyze our two-compartment model of a dendritic spine (Fig. $1 B$ ) in terms of the corresponding set of differential equations describing the time evolution of the receptor concentrations in the PSD and ESM (see Materials and Methods). Solutions of the model equations are used to investigate how receptor trafficking depends on the various biophysical parameters, including the rates of exocytosis/endocytosis $\sigma_{j}, k_{j}$, the rates of binding/ unbinding to scaffolding proteins $\alpha_{j}, \beta_{j}$, and the concentration of binding sites $L$ within the PSD. Here, the subscript $j$ denotes the receptor type with $j=\mathrm{I}$ for GluR $1 / 2$ and $j=\mathrm{II}$ for GluR2/3. These parameters are possible targets of second-messenger pathways initiated by a rise in intracellular $\mathrm{Ca}^{2+}$ during the induction phase of LTP/LTD. A basic assumption of our modeling approach is that there is a separation of timescales between the activation of the signaling pathways by the postsynaptic calcium signal during induction (seconds) and the subsequent expression 


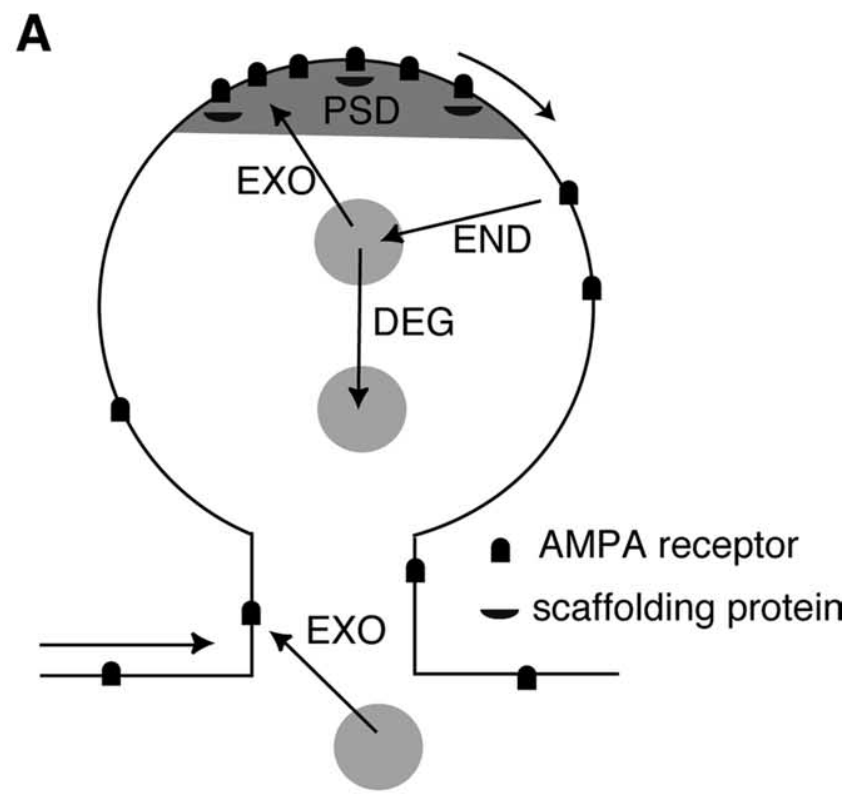

B

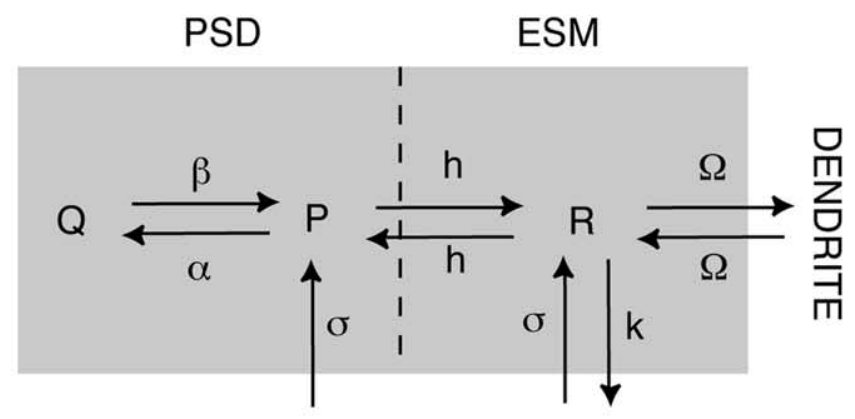

INTRACELLULAR

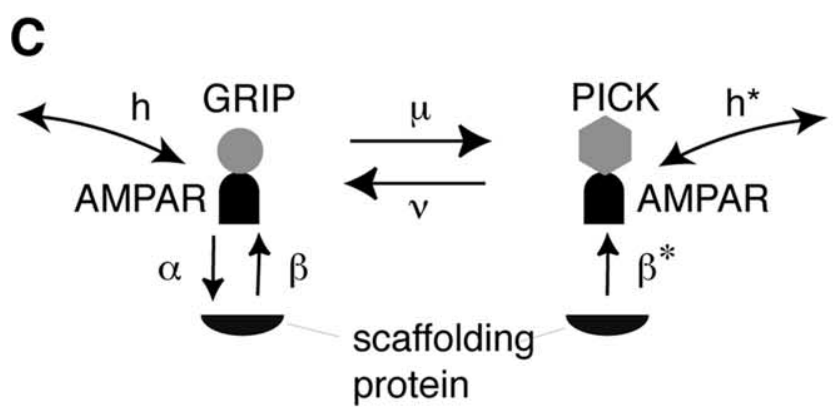

Figure 1. Compartmental model of AMPA receptor trafficking. $A$, Schematic of AMPA receptor trafficking at a dendritic spine. Receptors stored in intracellular pools are continually exchanged with surface receptors through exocytosis/endocytosis (EXO/END) and sorted for degradation (DEG). Surface receptors diffuse in the dendritic membrane and can be immobilized at the PSD through interactions with scaffolding proteins. $\boldsymbol{B}$, Simplified two-compartment model of a dendritic spine. Free receptors (concentration $P$ ) bind to scaffolding proteins within the PSD to form bound receptors (concentration $Q$ ) at a rate $\alpha$ (multiplied by the concentration of free binding sites) and unbind at a rate $\beta$. Free receptors flow between the PSD and ESM at a hopping rate $h$ and flow between the ESM and surface of the dendritic cable at a rate $\Omega$. Free receptors (concentration $R$ ) within the ESM are internalized at a rate $k$. Receptors are inserted into the PSD and ESM at a rate $\sigma$. Within each compartment, there are two distinct types of receptor corresponding to GluR1/2 (type I) and GluR2/3 (type II) heteromers, respectively. The rates of binding/unbinding, hopping, and exocytosis/endocytosis depend on receptor type. Only type II receptors undergo exocytosis in the $\mathrm{PSD}\left(\sigma_{1}=0\right)$ and only type I receptors undergo exocytosis in the ESM $\left(\sigma_{\|}=0\right)$. C, LTD model. GluR2/3 receptors are assumed to exist in two distinct states corresponding to association with GRIP and PICK proteins, respectively. Under of LTP/LTD (minutes). Under such an assumption, it is possible to study the mechanisms underlying the expression of LTP/LTD independently of the particular signaling pathways involved in induction. To interpret the results of our model in terms of experimentally determined changes in EPSPs during LTP/LTD, we identify the strength of a synapse with the total number of synaptic receptors. Thus, we neglect possible contributions to synaptic plasticity arising from changes in single-channel conductances (see Discussion).

Note that there have been a number of other recent, biophysically motivated models of LTP/LTD (Kitajima and Hara, 2000 Castellani et al., 2001; Abarbanel et al., 2002; Karmarkar and Buonomano, 2002; Shouval et al., 2002a,b; Hayer and Bhalla, 2005; Rubin et al., 2005; Shouval, 2005). However, these have tended to focus on the role of $\mathrm{Ca}^{2+}$ as an induction signal for bidirectional synaptic plasticity, rather than on the role of AMPA receptor trafficking in the expression of synaptic plasticity, in particular, the flow of receptors between the PSD and ESM. A few of the models do include receptor trafficking between the PSD and intracellular pools (Shouval et al., 2002b; Hayer and Bhalla, 2005; Shouval, 2005).

\section{Receptor trafficking under basal conditions}

The parameter values chosen for receptor trafficking under basal conditions are listed in Table 1. As some of the model parameters have yet to be determined experimentally (e.g., the rate at which AMPA receptors bind to and are released from scaffolding proteins), we select values for these parameters that produce results consistent with the known experimental data. Our choice for the rate of exocytosis is based on the work of Passafaro et al. (2001), which suggests time constants for exocytosis of $\sim 10-30 \mathrm{~min}$. Given a basal rate of exocytosis $\sigma \approx \kappa S$, where $S$ is the steady-state number of receptors in the intracellular pool, we take $\kappa$ to be the reciprocal of the Passafaro et al. (2001) time constant. For GluR2/3 receptors, we choose the rate of endocytosis approximately to balance the flux attributable to exocytosis, which yields the constitutive recycling of GluR2/3 heteromers at the dendritic spine. We take endocytic rates to be consistent with those suggested by Ehlers (2000). We choose the hopping rate $h$ of receptors flowing between the PSD and ESM so that approximately one-half of all synaptic receptors are mobile, consistent with the data of Groc et al. (2004) and Ashby et al. (2006). Because GluR2/3 receptors are inserted directly into the PSD, the majority of basal free receptors found in the PSD in our model are of this type. The steady state is thus maintained primarily by the constitutive recycling of GluR2/3 receptors, which involves a constant flux of receptors from the PSD to the ESM, where they are endocytosed and either reinserted into the membrane surface or degraded. We select the basal number of binding sites to approximately match the number of free receptors, and choose basal binding and release rates so that (1) nearly all of the binding sites are filled by GluR2/3 receptors, and (2) they are consistent with other known systems (Lauffenburger and Linderman, 1993). Note that taking the synapse to be unsaturated, that is, to have a significant fraction of free binding sites, would require unrealis-

basal conditions, the transition rate $\mu$ from the GRIP-associated state to the PICK-associated state is zero so that only GRIP-associated receptors exist and the model dynamics reduces to the kinetic scheme shown in $\boldsymbol{B}$. However, during the presentation of an LTD stimulus, $\mu$ increases so that some GRIP-associated receptors are converted to PICK-associated receptors. The latter are assumed to rapidly unbind from scaffolding proteins at a rate $\beta^{*}$, hop from the PSD to the ESM at a rate $h^{*}$, where they are endocytosed. This results in a net loss of receptors from the PSD. 
tically low binding affinities. This, in turn, makes it difficult to match the range of experimental data presented below. Estimates of receptor concentrations within the PSD range from 100 to 1000 receptors $\mu \mathrm{m}^{-2}$, whereas within the ESM they range from 1 to 20 receptors $\mu \mathrm{m}^{-2}$ (Nusser et al., 1998; Cottrell et al., 2000; Tanaka et al., 2005). The total number of receptors in the $\mathrm{PSD}$ depends on the size of the PSD and can vary from 1 to 200 . We choose a parameter regimen in which there are $\sim 40$ synaptic receptors under basal conditions and the concentration of extrasynaptic receptors is $\sim 25 \mu \mathrm{m}^{-2}$. Finally, the background concentration of GluR1/2 receptors in the dendrite is taken to be $\bar{R}_{\mathrm{I}}=10 \mu \mathrm{m}^{-2}$, whereas the corresponding background concentration of GluR2/3 receptors is taken to be zero. This is based on the assumption that GluR2/3 receptor trafficking is local to the synapse, whereas trafficking of GluR1/2 receptors occurs extrasynaptically. It should be possible to determine $\bar{R}_{\mathrm{I}}$ self-consistently by considering a multisynapse version of our model, in which extrasynaptic receptors diffuse between synapses distributed on the surface of a dendritic cable.

In Figure 2, we show how the steady-state number of GluR1/2 and GluR2/3 receptors in the PSD depends on various trafficking parameters as determined by Equations 5-8 in Materials and Methods. Figures $2 A-D$ show how total receptor number varies with the rates of exocytosis and endocytosis. As one expects, the number of receptors is an increasing (decreasing) function of the rate of exocytosis (endocytosis). However, this dependence is weak unless free receptors tend to be confined within their compartment, that is, the hopping rates $h_{j}, \Omega_{127}$ have to be sufficiently small. Note that the number of free and bound receptors within the PSD are approximately equal. In Figure $2 E$, we show how the PSD binding sites become saturated with GluR2/3 receptors as the ratio of binding to unbinding rates $\alpha_{\text {II }} / \beta_{\text {II }}$ increases.

The dependence of synaptic strength on exocytosis/endocytosis has been investigated experimentally by pharmacologically blocking the insertion or internalization of receptors in a CA1 hippocampal cell (Luscher et al., 1999). For example, loading a cell with Botox disrupts exocytosis by inactivating v-SNAREs (vesicle-soluble $N$-ethylmaleimide-sensitive factor attachment protein receptors), and causes a 40\% reduction in AMPA receptor EPSCs over 20 min. However, a targeted inhibition of endocytosis results in a twofold increase in the AMPA receptor EPSCs over a similar timescale. If we assume that the amplitude of a recorded EPSP is approximately proportional to the number of AMPA receptors from which the recording is made, then the time course of the number of AMPA receptors should approximately follow the time course of the recorded EPSPs. Thus, the Luscher et al. (1999) data suggest that, when exocytosis is blocked, the number of AMPA receptors at the PSD should approximately halve, and when endocytosis is blocked, the number of receptors should approximately double.

We can reproduce the results of Luscher et al. (1999) in our model by setting to zero either exocytosis $\left(\sigma_{\mathrm{I}}=\sigma_{\mathrm{II}}=0\right)$ or endocytosis $\left(k_{\mathrm{I}}=k_{\mathrm{II}}=0\right)$ and determining the resulting timedependent decrease or increase in the number of synaptic receptors. We find that blocking exocytosis without changing any other parameters of the model leads to a loss of about one-half of the receptors in the PSD (Fig. $3 A$ ), whereas we find a doubling of receptors in the PSD after endocytosis is blocked (Fig. $3 B$ ). Note that, in the latter case, one might expect blocking of endocytosis within the dendrite of a cell to raise the background concentrations $\bar{R}_{\mathrm{j}}$ of AMPA receptors. However, the results shown in Figure $3 B$ are insensitive to increases in background concentration, at least at the given basal hopping rates. Interestingly, the time courses predicted by our model are also similar to those found by Luscher et al. (1999), although the reduction in response to exocytic blockage is slightly faster in our model and the increase in response to endocytic blockage is slightly slower. It should be noted that, over the time course shown in Figure $3 A$, the receptor concentration has not yet reached a steady state, that is, the asymptotic value shown in Figure $3 A$ is larger than the steady-state value shown in Figure $2 D$ for zero exocytosis. Our model thus predicts that when exocytosis is completely blocked the number of synaptic receptors should continue to decrease at a slow rate over several hours to reach steady state. This slower component represents the unbinding of receptors from scaffolding proteins and their ultimate escape from the PSD to the ESM boundary.

\section{Increase of synaptic receptor concentration during LTP}

There is growing experimental evidence to suggest that a major contribution to the expression of early-phase LTP is the trafficking of GluR1/2 receptors into the PSD (Song and Huganir, 2002; Bredt and Nicoll, 2003; Choquet and Triller, 2003; Collingridge et al., 2004). This is likely to involve an activity-dependent increase in the rate of exocytosis of GluR1/2 receptors into the extrasynaptic membrane, and a corresponding increase in the number and/or affinity of receptor binding sites within the PSD. A number of PSD-95/Discs large/zona occludens-1 (PDZ)-domaincontaining proteins have been identified as playing a role in the regulation of AMPA receptor trafficking. PDZ domains are protein-protein interaction motifs that bind to the intracellular C-terminal domain of their target proteins. One example of a PDZ-domain-containing protein that binds directly to GluR1/2 is SAP-97 (synapse-associated protein 97), which has been implicated in the trafficking of AMPA receptors into dendritic spines after phosphorylation by calcium/calmodulin-dependent protein kinase II (CaMKII) (Hayashi et al., 2000; Shi et al. 2001; Wu et al., 2002; Mauceri et al., 2004). CaMKII is itself activated by an activity-dependent rise in intracellular $\mathrm{Ca}^{2+}$ concentration under LTP stimulus protocols (Lisman 2003; Malenka and Bear, 2004).

GluR1/2 receptors also associate with TARPs (transmembrane AMPA receptor regulatory proteins) such as stargazin. Interestingly, stargazin binds with the PDZ-domain-containing 

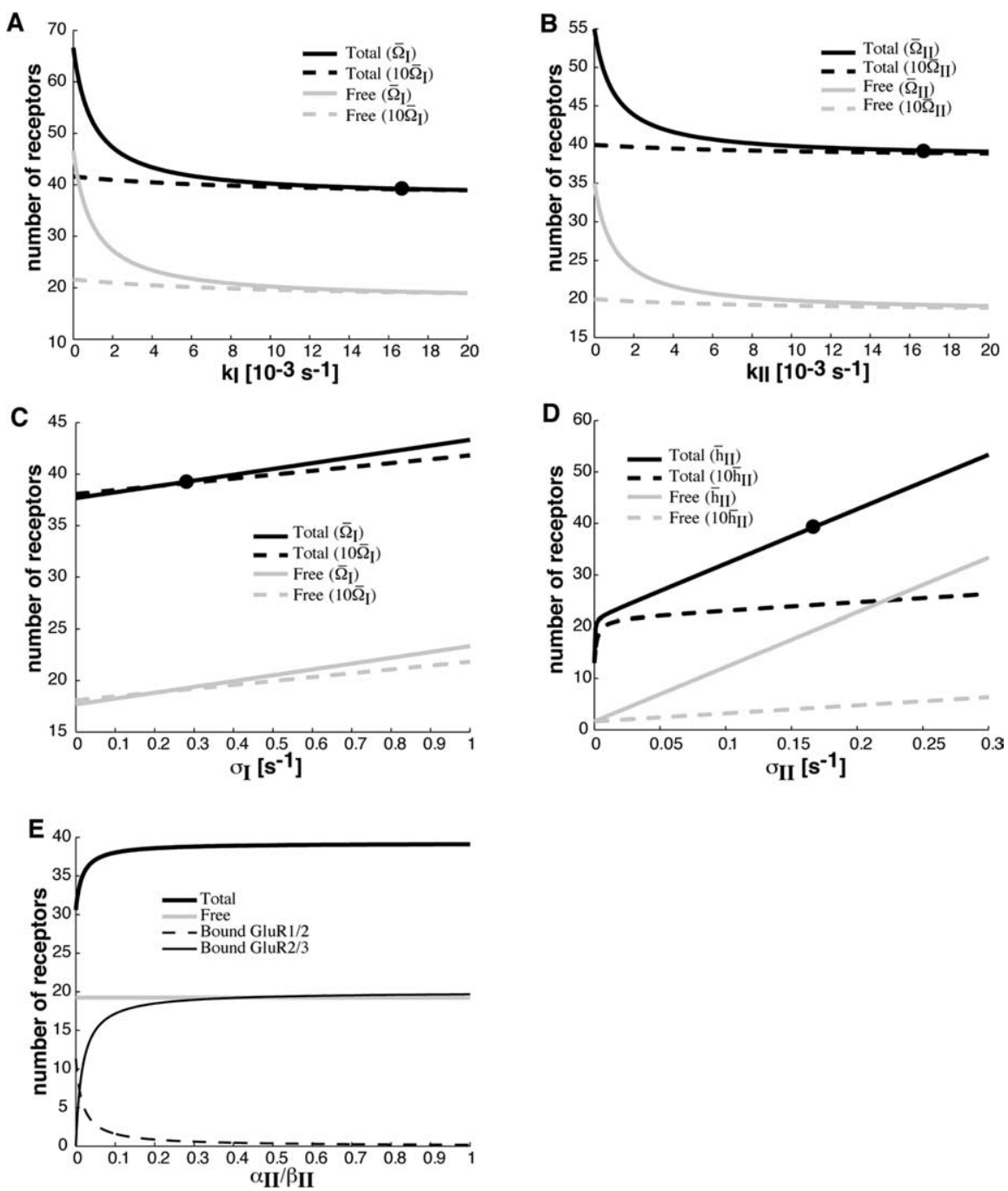

Figure 2. Steady-state behavior of synaptic receptor number as a function of trafficking parameters. All parameters are at their basal values as listed in Table 1 unless specified otherwise. $\boldsymbol{A}, \boldsymbol{B}$, Variation of receptor number with rate of endocytosis $k_{i t} j=I, I I$. The solid curves show number of receptors in the PSD at the basal hopping rate between the ESM and dendrite, denoted by $\bar{\Omega}_{j}$ whereas the dashed curves show corresponding receptor numbers when $\bar{\Omega}_{j}$ is increased by a factor of 10 . Receptor number decreases with increasing endocytosis, and dependence becomes weaker with increasing hopping rate between the ESM and dendrite. C, Variation of receptor number with rate of exocytosis $\sigma_{1}$. The solid curves show number of receptors in the PSD at basal hopping rates, whereas dashed curves show corresponding receptor numbers when $\bar{\Omega}_{\mathrm{I}}$ is increased by a factor of 10 . Receptor number increases with increasing exocytosis, and dependence becomes weaker with increasing hopping rate between the PSD and ESM. $\boldsymbol{D}$, Variation of receptor number with rate of exocytosis $\sigma_{\|}$. The solid curves show number of receptors in the PSD at basal hopping rate between PSD and ESM, denoted by $\bar{h}_{\mathrm{II}}$, whereas the dashed curves show corresponding receptor numbers when $\bar{h}_{\mathrm{II}}$ is increased by a factor of 10 . Receptor number increases with increasing exocytosis, and dependence becomes weaker with increasing hopping rate between the PSD and ESM. The nonlinear dependence of the total number of receptors near $\sigma_{\|}=0$ represents the transition from unsaturated to saturated binding sites. In $\boldsymbol{A}-\boldsymbol{D}$, the point corresponding to basal conditions is indicated by a filled circle on the solid black curve. Note that the number of free receptors is approximately equal to one-half the total number of receptors. $\boldsymbol{E}$, Variation of receptor number with the ratio of type II binding rate to unbinding rate. Total receptor number increases with increasing $\alpha_{\|} / \beta_{\|}$and saturates near $\alpha_{\|} / \beta_{\|}=1$, indicating that all binding sites are full. This is attributable to the large number of free GluR2/3 receptors in the PSD, which fill available binding sites and replace bound GluR1/2 receptors. Dependence is weak near the basal value of $\alpha_{\|} / \beta_{\|}=10$ (data not shown), indicating a strong affinity of GluR2/3 receptors for binding sites. Receptor numbers are relatively insensitive to $\alpha_{I} / \beta_{1}$ (data not shown).

protein PSD-95, a major scaffolding protein of the PSD (Chen et al., 2000; Schnell et al., 2002). Disrupting the ability of stargazin to interact with PSD-95 leads to a massive decrease in synaptic AMPA receptors and an increase in extrasynaptic receptors. Moreover, an overexpression of PSD-95 enhances the number of synaptic AMPA receptors (El-Husseini et al., 2000; Schnell et al., 2002), whereas removal of PSD-95 from the synapse by depalmitoylation depletes synaptic AMPA receptors (El-Husseini et al.,
2002). However, increasing the expression of stargazin without changing the level of PSD-95 increases the number of extrasynaptic AMPA receptors without changing the strength of a synapse (Schnell et al., 2002). It is thus hypothesized that the interaction between stargazin and AMPA receptor subunits is important for the surface delivery of AMPA receptors, whereas the interaction between stargazin and PSD-95 is important for the synaptic targeting of the receptors. Recent evidence suggests that phosphorylation of stargazin by CaMKII facilitates the interaction with PSD-95 and is a critical component of LTP (Tomita et al., 2005).

Motivated by the above experimental findings, we numerically solve the kinetic Equations 1-4 of our receptor trafficking model to determine the time-dependent variation in the GluR1/2 receptor concentration in response to increases in the rate of exocytosis $\sigma_{\mathrm{I}}$, the affinity $\alpha_{\mathrm{I}}$ of binding sites in the PSD, and the hopping rate $h_{\mathrm{I}}$ between the PSD and ESM (under the assumption that the interaction between PSD-95 and stargazin facilitates the entry of receptors into the PSD) (see Materials and Methods). We assume that such changes occur rapidly relative to the time course associated with the redistribution of AMPA receptors. This is based on experimental data indicating that CaMKII, one of the crucial components of the signaling pathways involved in the induction of LTP, acts like a rapid molecular switch (Zhabotinsky, 2000; Lisman and Zhabotinsky, 2001; Lisman et al., 2002). It is important to emphasize, however, that the detailed molecular mechanisms underlying the trafficking of AMPA receptors during LTP are still far from clear. One of the useful features of our mathematical model is that it allows us to explore a given hypothesis regarding the regulation of receptor trafficking during LTP.

To model changes in the rate of exocytosis, we set $\sigma_{\mathrm{I}}=\kappa_{\mathrm{I}} S_{\mathrm{I}}$, where $S_{\mathrm{I}}$ is the total number of GluR1/2 receptors in the intracellular pool and $\kappa_{\mathrm{I}}$ is the rate of exocytosis per receptor (see Eq. 4). We assume that, in steady state, the rate of exocytosis is equal to the rate of receptor synthesis, which we denote by $\delta_{\mathrm{I}}$. A sudden increase in $\kappa_{\mathrm{I}}$, and hence $\sigma_{\mathrm{I}}$, results in the rapid insertion of intracellular receptors into the extrasynaptic membrane, and a corresponding reduction in $S_{\text {I }}$ so that, after an initial transient, the rate of exocytosis returns to the steady-state value $\delta_{\text {I }}$. (Increasing the rate of receptor synthesis $\delta_{\mathrm{I}}$ would lead to a persistent change in the rate of receptor insertion, but does not produce realistic time courses for LTP.) Therefore, to maintain an increase in the number of synaptic receptors, we further assume that LTP involves an increase in the concentration $L$ of 

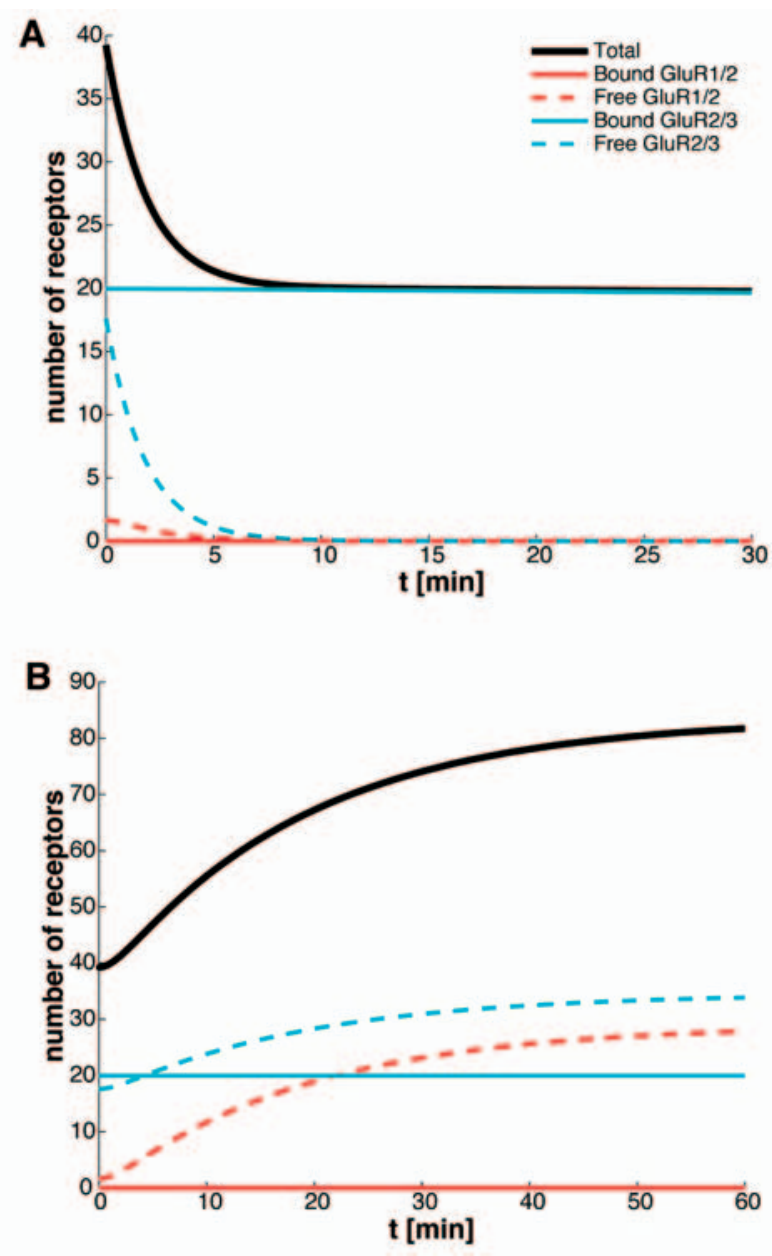

Figure 3. Time course of AMPA receptors after blocking exocytosis/endocytosis. $A$, Blocking exocytosis. With receptors at basal steady state at time $t<0$, exocytosis is blocked by setting $\sigma_{j}=0(j=1,2)$ at $t=0$. The number of AMPA receptors in the PSD almost halves in $<10 \mathrm{~min}$ (because of the loss of free receptors) and decreases to $\sim 1$ over $\sim 10 \mathrm{~d}$ (data not shown). $\boldsymbol{B}$, Blocking endocytosis. Endocytosis is blocked by setting $k_{j}=0(j=1,2)$ at $t=0$. The number of AMPA receptors in the PSD nearly doubles within $1 \mathrm{~h}$ (because of the addition of free receptors) and reaches a new steady-state value of $\sim 84$. These results are consistent with those of Luscher et al. (1999).

binding sites. One proposal for how this could occur is that AMPA receptors delivered to the synapse bring with them socalled "slot" proteins that provide the additional binding sites (Malinow, 2003). We model this by supplementing Equations 1-4 with the following dynamical equation for the concentration $L$ of binding sites:

$$
\frac{d L}{d t}=-c \frac{d S_{\mathrm{I}}}{d t}=c\left[\kappa_{\mathrm{I}} S_{\mathrm{I}}-\delta_{\mathrm{I}}\right] .
$$

That is, the rate of increase in $L$ is taken to be proportional to the rate at which the intracellular store of GluR1/2 receptors is depleted, with $c$ a dimensionless constant. Solving Equations 4 and 11 shows that $L$ increases asymptotically to a new steady-state value. It is important to note that $L$ only satisfies Equation 11 while the rate of exocytosis per receptor $\kappa_{\mathrm{I}}$ is maintained above basal levels. When the latter returns to its basal value, perhaps because of deactivation of the CaMKII switch, the number of intracellular receptors $S_{\mathrm{I}}$ recovers according to Equation 4, whereas $L$ is now held fixed. [Over longer timescales of hours and days, additional mechanisms are needed to stabilize $L$ with re- spect to the constitutive recycling of scaffolding proteins (see below and Discussion).]

In Figure $4, A$ and $B$, we plot the resulting time courses for the total number of receptors in the PSD and ESM, respectively. Also shown in Figure $4 A$ is the increase in the number of scaffolding proteins within the PSD, which asymptotically approaches a new steady-state value over the time course of a few minutes. The corresponding depletion of the intracellular pool is shown in Figure $4 B$. If we assume that the number of synaptic AMPA receptors is proportional to the size of EPSPs, then the profile shown in Figure $4 A$ is consistent with recordings from single synapses (Petersen et al., 1998; O'Connor et al., 2005) and field EPSPs (Bliss and Lomo, 1973; Hanse and Gustafsson, 1992). That is, typical EPSPs recorded during LTP show a sharp, initial rise that peaks in $\sim 30-60 \mathrm{~s}$ at $\sim 200-300 \%$ of the baseline response, and then settles at a slower rate to $\sim 150-200 \%$ of baseline response. In Figure 4, $C$ and $D$, we show the time-dependent variation in the number of synaptic and extrasynaptic receptors in response to changes in the rate of exocytosis alone, without a corresponding increase in binding sites, binding affinity, or hopping rate. It can be seen that there is a large increase in the number of extrasynaptic receptors but only a small transient increase in the number of synaptic receptors. This is consistent with what happens when there is an overexpression of stargazin without a corresponding increase in PSD-95 (Schnell et al., 2002). That is, stargazin can facilitate transport of AMPA receptors to the surface but is not able to target synapses unless it can interact with PSD-95.

It is important to emphasize that the distribution of receptors has not reached a steady state over the time course of a few minutes shown in Figure $4, A$ and $B$. For during this period, the rate of exocytosis $\sigma_{\mathrm{I}}$ has returned to its basal level, which implies that there are not enough free GluR1/2 receptors to maintain equilibrium with the receptors bound to the newly activated binding sites within the PSD. Thus, over a longer time period of several hours, the GluR1/2 receptors are slowly exchanged with GluR2/3 receptors through the process of constitutive recycling (Fig. $4 E$ ). Such an exchange has been observed experimentally and has been suggested as a mechanism for maintaining bidirectional synaptic plasticity (McCormack, et al., 2006). However, to stabilize the strength of a synapse over these longer timescales, additional mechanisms are necessary. In particular, the slow turnover of scaffolding proteins within the PSD (Okabe et al., 1999; Inoue and Okabe, 2003) suggests that the increase in the concentration $L$ of binding sites through the trafficking of slot proteins is only temporary and that $L$ eventually returns to basal levels. One possible way of maintaining the increased number of binding sites is through structural changes in the dendritic spine (see Discussion).

\section{Decrease of synaptic receptor concentration during LTD}

Many synapses that exhibit LTP also exhibit LTD under appropriate stimulus conditions. A common stimulus protocol for inducing LTD is a prolonged repetitive synaptic stimulation at 0.5-5 Hz involving 900 stimuli (Dudek and Bear, 1992, 1993). Whether LTP or LTD occurs depends on the spatiotemporal properties of the intracellular $\mathrm{Ca}^{2+}$ signal (Malenka and Bear, 2004; Rubin et al., 2005). LTP is induced by a large, fast increase of intracellular $\mathrm{Ca}^{2+}$ concentration in the dendritic spine, whereas LTD is induced by a moderate, slow increase that may be accompanied by $\mathrm{Ca}^{2+}$ release from intracellular stores (Franks and Sejnowski, 2002). The LTD induction signal triggers signaling cascades that involve the activation of enzymes such as PKC (protein kinase C), PP1 (protein phosphatase 1), and calcineurin 

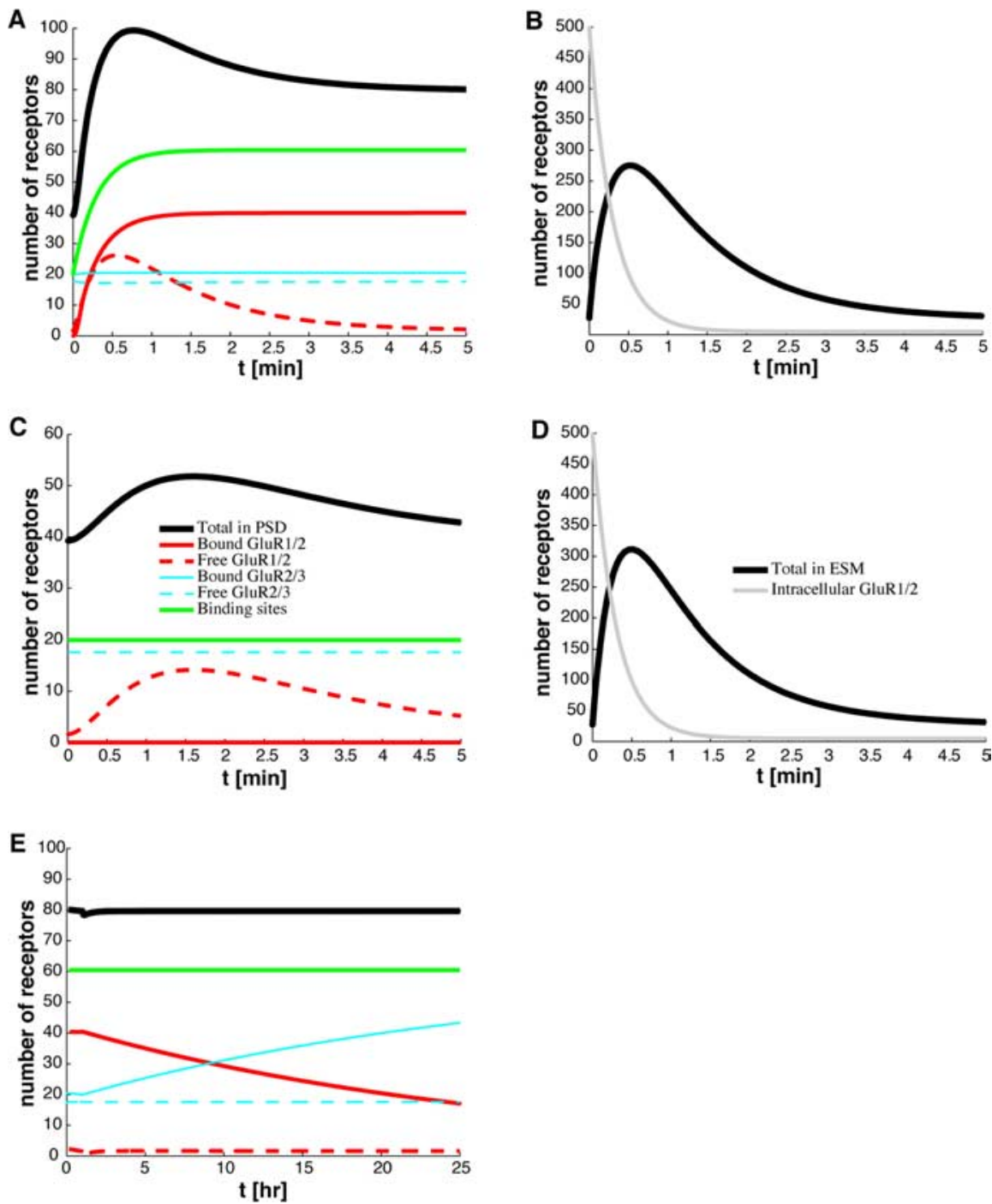

Figure 4. Time course of AMPA receptors during LTP. $A, B$, With receptors at basal steady state for $t<0$, LTP is induced at time $t=0$ by making the following changes to the basal GluR $1 / 2$ parameter values listed in Table 1 and numerically solving Equations 1-4: binding rate $\alpha_{1}=0.001 \mu \mathrm{m}^{2} \mathrm{~s}^{-1}$, exocytic rate per receptor $\kappa_{\mathrm{L}}=0.0556 \mathrm{~s}^{-1}$, and hopping rate $h_{1}=0.01 \mu \mathrm{m} \mathrm{s}-1$. Binding site trafficking is also activated according to Equation 11 with $c=0.65$. $\boldsymbol{A}$ shows the variation in the total number of receptors (solid black curve) and the number of binding sites (solid green curve) within the PSD, whereas $\boldsymbol{B}$ shows the corresponding variation in the total number of receptors in the ESM (solid black curve) and the number of intracellular receptors (solid gray curve). The contributions from the various receptor types are also shown in $\boldsymbol{A}$. The number of receptors in the ESM rises transiently because of the exocytosis of intracellular GluR1/2 receptors. Some of these newly exocytosed receptors enter the PSD and are immobilized by the newly available binding sites. These results are consistent with experimentally recorded EPSPs after LTP induction (Hanse and Gustafsson, 1992; 0'Connor et al., 2005). C, D, Time course of synaptic receptors ( $\boldsymbol{C}$ ) and extrasynaptic receptors ( $\boldsymbol{D}$ ) without synaptic targeting. Labeling of various curves is as in $\boldsymbol{A}$ and $\boldsymbol{B}$. With receptors at basal steady state at time $\boldsymbol{t}<$ 0 , the rate of GluR1/2 exocytosis is increased by setting $\kappa_{1}=0.0556 \mathrm{~s}^{-1}$ at time $t=0$. However, the hopping rate and binding affinity of GluR $1 / 2$ receptors and the number of binding sites remain at basal levels. The concentration in the ESM rises transiently as GluR1/2 receptors from the intracellular pool are exocytosed there, as in the case of LTP, but now there is only a small transient rise in the number of synaptic receptors. These results illustrate that both exocytosis and synaptic targeting are required for LTP. This is consistent with the suggestion that stargazin plays a role in transporting GluR1/2 receptors to the membrane surface, whereas its interaction with PSD-95 is required for synaptic targeting (Schnell et al., 2002). $\boldsymbol{E}$, Exchange of GluR1/2 and GluR2/3 AMPA receptors. After $1 \mathrm{~h}$ of maintaining LTP parameters, all parameters are returned to their basal values except the binding site concentration $L$, at which time GluR2/3 receptors begin to replace GluR1/2 receptors at the binding sites. These results are consistent with those of McCormack et al. (2006).

(Winder and Sweatt, 2001; Song and Huganir, 2002; Steinberg et al., 2006). Just as LTP is associated with an increase in the number of synaptic AMPA receptors because of the influx of receptors from the extrasynaptic membrane, LTD appears to involve a loss of receptors from the PSD because of modifications in constitutive recycling (Carroll, et al., 1999a,b; Beattie et al., 2000; Lin et al., 2000; Man et al., 2000). One triggering mechanism is thought to be phosphorylation of GluR2/3 synaptic receptors, which disrupts the interactions with the stabilizing scaffolding protein GRIP/ABP and allows for association with PICK1 (Chung et al., 2000; Matsuda et al., 2000; Kim et al., 2001; Perez et al., 2001; Lu and Ziff, 2005). PICK1 mediates the loss of AMPA receptors at the PSD, because the overexpression of PICK1 at synapses is correlated with a decrease in membrane expression of AMPA receptors. It has been suggested that the switch from association with GRIP/ABP to PICK1 plays a role in untethering receptors from PSD binding sites, escorting them out of the PSD, and then facilitating internalization of the receptors once they have reached the ESM (Song and Huganir, 2002; Steinberg et al., 2006). Another possible mechanism for reducing the number of synaptic AMPA receptors during LTD is through the removal of scaffolding proteins from the PSD. There is some indirect experimental evidence for this, namely, that NMDA receptor activation can lead to the ubiquitination and subsequent degradation of the scaffolding protein PSD-95 (Colledge et al., 2003). The removal of a scaffolding protein releases the associated bound receptor, which can then diffuse out of the PSD and be internalized through endocytosis.

The above role of GluR2/3 receptor trafficking in LTD is consistent with data suggesting that, under basal conditions, the majority of receptors within the PSD are of this type (Shi et al., 2001; McCormack et al., 2006). However, experimental studies in knock-out mice provide evidence that dephosphorylation of GluR1 subunits is an essential component of hippocampal LTD (Lee et al., 1998, 2000, 2003). This suggests that there may be a number of distinct mechanisms for the removal of synaptic receptors during LTD (Bredt and Nicoll, 2003; Malenka and Bear, 2004). As in the case of LTP, we can use our model to explore various hypotheses regarding how changes in receptor trafficking generate responses that are consistent with those observed during LTD. Here, we will focus on the role of GluR2/3 under the assumption that basal levels of GluR1/2 within the PSD are low. To proceed, we extend our basic model by assuming that GluR2/3 receptors within the PSD exist in two distinct states corresponding to association with GRIP/ABP and PICK1, respectively (see Materials and Methods). Suppose that under basal conditions the transition rate $\mu$ from the GRIPassociated state to the PICK-associated state is negligible $(\mu=0)$ so that the number of receptors in the PICK-associated state is 
approximately zero. The receptor concentrations then satisfy the original set of Equations 1-4. We now assume that, during the induction phase of LTD, the transition rate $\mu$ increases, leading to the conversion of some bound receptors to the PICK-associated state. We further assume that the change in $\mu$ is rapid compared with the timescale of receptor trafficking, and is maintained during the presentation of the LTD stimulus. ( $\mu$ rapidly returns to zero once the stimulus is removed.) The combined system of GRIP-associated and PICK-associated GluR2/3 receptors within the PSD now evolves according to Equations 9 and 10. In particular, PICKassociated receptors rapidly untether from their binding sites and hop to the ESM where they are endocytosed, resulting in a reduction in the number of receptors within the PSD. However, on its own, this mechanism would not maintain LTD once the low-frequency stimulus is removed, because there is currently no evidence for a bistable switch analogous to CaMKII that would allow levels of phosphorylation to persist. Therefore, receptors would convert back to the GRIPassociated state and the synapse would recover. To have a persistent reduction in synaptic strength, we assume that, as receptors untether from binding sites, these sites are removed at some rate $\gamma$. We thus supplement Equations 1a, 2a, 9, and 10 of the extended model by the following equation for the concentration $L$ of binding sites:

$$
\frac{d L}{d t}=-\gamma\left[L-Q_{\mathrm{I}}-Q_{\mathrm{II}, a}-Q_{\mathrm{II}, b}\right],
$$

where $Q_{\mathrm{I}}$ is the concentration of GluR1/2 receptors and $Q_{\mathrm{II}, a}$ and $Q_{\mathrm{II}, b}$ are, respectively, the concentrations of GRIP-associated and PICKassociated GluR2/3 receptors bound to scaffolding proteins within the PSD. This equation, which takes the rate of decrease of $L$ to be proportional to the concentration of free binding sites within the PSD, only holds during the presentation of the LTD stimulus; once the stimulus is removed, $L$ stops decreasing. Under basal conditions, the binding sites are almost fully occupied. However, during LTD, GRIP-associated receptors are converted to PICK-associated receptors so that $Q_{\mathrm{II}, a}$ decreases and $Q_{\mathrm{II}, b}$ increases. Because PICK-associated receptors are more likely to unbind from scaffolding proteins, we find that $Q_{\mathrm{II}, a}$ decreases faster than $Q_{\mathrm{II}, b}$ increases. The net result is that $L$ decreases because of the freeing of binding sites. Once the LTD stimulus is removed, all receptors convert back to the GRIP-associated state and all of the remaining binding sites become reoccupied.

We numerically solve the extended receptor trafficking model given by equations $1 \mathrm{a}, 2 \mathrm{a}, 9,10$, and 12 to determine the timedependent variation in synaptic receptor concentration during
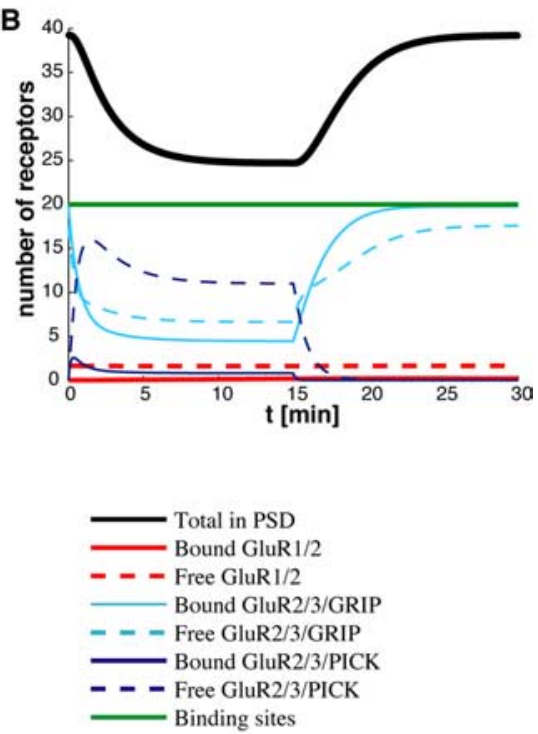

Figure 5. Time course of AMPA receptors during and after LTD. The variation in the total number of receptors (solid black curves) and binding sites (solid green curves) in the PSD are shown together with contributions from the various receptor types. $\boldsymbol{A}$, 列 within the PSD evolve according to Equations 9 and 10 and the concentration of binding sites decreases according to Equation 12 . parameters are as listed in Table 1. GluR2/3-GRIP is rapidly converted to GluR2/3-PICK during the first few minutes of LTD; afterward, this conversion occurs at a slower rate. Bound GluR2/3-PICK quickly releases from binding sites, and free GluR2/3-PICK 作 (he PSD during LTD with moderate frequency stimulus. LTD is induced as in $A$, except that $\gamma=0 \mathrm{~s}^{-1}$ throughout. receptors in the PSD reture (1992), their Fig. 2 B. C Saturation of LTD. LTD is induced as in $\boldsymbol{A}$, except that it is followed by 45 min of basal activity, and this

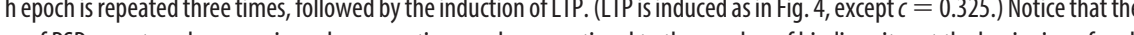
epoch. Saturation occurs because only bound, and not free, receptors are lost during LTD. The variation in the number of synaptic receptors is consistent with Dudek and Bear (1993), their Fig. 7.

LTD. Figure $5 A$ shows the time course of the total number of receptors for the various receptor types. The synapse is assumed to be in steady state under basal conditions for $t<0$, with a negligible concentration of PICK-associated receptors $(\mu=0)$. We assume that a low-frequency stimulus is applied for $900 \mathrm{~s}$ during which $\mu>0$. It can be seen that there is a conversion of GRIP to PICK during the presentation of the stimulus, with a partial recovery after the stimulus is removed. The steady-state receptor concentration has decreased, however, because of the removal of binding sites. Interestingly, our model can reproduce a variety of experimental results. For example, Dudek and Bear (1992) showed that increasing the frequency of the stimulus from 3 to $10 \mathrm{~Hz}$, say, can lead to a transient reduction in synaptic strength rather than LTD. One way to generate this in our model is to assume that the stimulus induces the conversion of GRIP to PICK, but the number of binding sites is not reduced (Fig. $5 B$ ). In another experiment, Dudek and Bear (1993) showed how a sequence of low-frequency stimulations each separated by $\sim 45$ min can induce a saturating sequence of LTD. This result can also 
be reproduced by our model, with the saturation arising from the fact that, even if most binding sites are removed, there are still free receptors present.

\section{Discussion}

In this study, we presented a mathematical model of AMPA receptor trafficking at a synapse that provides a general theoretical framework for investigating the role of trafficking in the expression of synaptic plasticity. The behavior of the model depends on various trafficking parameters that could be targets of secondmessenger pathways activated by the postsynaptic calcium signal during the induction of LTP/LTD. We used our model to explore the consequences of targeting different sets of trafficking parameters, and showed how this can reproduce a wide range of experimental data: (1) the increase/decrease in synaptic strength after pharmacologically blocking endocytosis/exocytosis (Luscher et al., 1999), (2) the time course of changes in synaptic strength during the expression of LTP (Bliss and Lomo, 1973; Hanse and Gustafsson, 1992; O'Connor et al., 2005), (3) the slow exchange of GluR1/2 receptors with GluR2/3 receptors after potentiation (McCormack et al., 2006), (4) the time course of changes in synaptic strength during the expression of LTD and its dependence on frequency of stimulation (Dudek and Bear, 1992, 1993), and (5) the saturation of LTD induced by a sequence of lowfrequency stimuli (Dudek and Bear, 1993).

Constraining our model to reproduce these results using physiologically reasonable parameter values allows us to make experimentally testable predictions regarding AMPA receptor trafficking and its regulation during LTP/LTD. First, there should be a significant fraction of mobile receptors in the PSD under basal conditions, consistent with the data of Groc et al. (2004) and Ashby et al. (2006). This, in turn, requires a barrier to diffusion at the PSD-ESM boundary, as previously suggested by Triller and Choquet $(2003,2005)$. Second, the exocytosis of intracellular GluR1/2 receptors during LTP only generates realistic time courses if it is combined with synaptic targeting (e.g., increases in the hopping rate across the PSD-ESM barrier and the rate of binding to scaffolding proteins). This is consistent with the suggested role of stargazin and its interaction with PSD-95 (Schnell et al., 2002). Moreover, depletion of the intracellular pool suggests that the increased rate of exocytosis is only temporary. Therefore, to have persistent early-phase LTP, it is necessary to increase the number of binding sites within the PSD, perhaps via the delivery of "slot" proteins by incoming AMPA receptors (Malinow, 2003). Third, the unbinding of GluR2/3 receptors from scaffolding proteins in the PSD (perhaps by exchange of GRIP with PICK) and subsequent endocytosis from the ESM is not sufficient to generate persistent LTD. A realistic LTD time course can be generated, however, if there is also a gradual decrease in the number of binding sites, that is, a removal of "slot" proteins. One of the interesting features of our model is that a number of experimental results can be obtained without any additional tuning of the model. These include the slow exchange of GluR1/2 with GluR2/3 receptors during LTP, and the saturation of LTD. Of course, our results may be a consequence of the various simplifying assumptions of our model, which we now discuss in more detail.

\section{Effects of diffusion}

One major simplification is to ignore the effects of diffusion within the PSD and ESM. This was motivated by the observation that given physiologically reasonable values for the diffusivity of mobile receptors in each of the compartments (Groc et al., 2004), lateral membrane diffusion is relatively fast. In particular, the fluxes involved in receptor trafficking can be maintained by small concentration gradients so that the distribution of receptors within a compartment is approximately spatially uniform. One consequence of fast diffusion is that the relatively high levels of free receptors found in the PSD cannot be maintained without some form of barrier between the PSD and ESM. Such a barrier can be incorporated into a diffusion model by requiring that the diffusive flux across the boundary between the PSD and ESM is proportional to the difference in concentrations on either side of the boundary. The associated hopping rate limits the flux across the PSD-ESM junction and allows the free receptor concentrations to be discontinuous there. An alternative mechanism for localizing free receptors within the PSD would be to have a sufficiently small diffusivity. Numerical simulations of a diffusionbased version of our model suggest that the required diffusivity lies outside the range of measured values for mobile receptors within the PSD (Groc et al., 2004). One important aspect of dendritic spines that a diffusion-based model could take into account is the effect of spine geometry on receptor trafficking, in particular the role of the spine neck in restricting the flow of receptors from the ESM to the dendritic shaft, as recently observed experimentally (Ashby et al., 2006). In our simplified model, we represented the effect of the spine neck phenomenologically as an effective hopping rate $\Omega$. A diffusion model could be used to determine $\Omega$ from first principles.

\section{Single-channel conductance}

To interpret the results of our model in terms of experimentally determined EPSP amplitudes, we assumed that the size of an EPSP is simply proportional to the total number of synaptic receptors. However, there is experimental evidence to suggest that direct phosphorylation of existing AMPA channels and a resulting increase in single-channel conductance can also contribute to LTP expression (Benke et al., 1998; Poncer et al., 2002). An analogous result may hold for LTD, because dephosphorylation of AMPA receptors can lead to a decrease in single-channel conductance (Banke et al., 2000). Recently, a combined experimental and modeling study of LTP in CA1 neurons explored how experimentally observed EPSP amplitudes in LTP can be accounted for by changing receptor number, channel conductance, or glutamate release in a detailed computational model of CA1 cells (Holmes and Grover, 2006). The size of an EPSP was found to depend sublinearly on the number of AMPA receptors, leading to the conclusion that the change in receptor number required to account for the largest observed EPSPs in LTP is unrealistically high and, hence, that more than one mechanism is likely to be involved in the expression of LTP. Note that this study was concerned with the static dependence of synaptic strength on fixed synaptic receptor numbers and conductances, rather than with dynamical mechanisms that account for the time course of LTP expression. Developing an extension of our own model that includes both the dynamics of receptor trafficking and changes in single-channel conductances could provide additional insights into the relative contributions of these two processes to LTP/LTD.

\section{Slot proteins and synaptic stabilization}

Although many scaffolding-related proteins have been identified (Song and Huganir, 2002), little is known about how these proteins act in concert to regulate and maintain AMPA receptor numbers at synapses. We modeled these proteins phenomenologically in terms of binding sites, which represent complexes 
able to immobilize AMPA receptors, much like the "slot" proteins hypothesized by Shi et al. (2001). We found that to stabilize changes in synaptic AMPA receptor numbers with respect to receptor turnover (which occurs on the order of minutes), it was necessary to transport binding sites to or from the synapse. However, it is known that scaffolding proteins themselves undergo constitutive recycling over a period of several hours (Okabe et al., 1999; Inoue and Okabe, 2003). This implies that without additional processes the number of binding sites would eventually return to basal values. Therefore, another level of synaptic stabilization is required to maintain changes in synaptic strength over hours and days. One such mechanism could involve structural changes in the dendritic spine driven by F-actin and protein synthesis (Matus, 2000; Kasai et al., 2003; Lamprecht and LeDoux, 2004). For example, enlargement of the spine head could accommodate an increase in the number of binding sites during LTP, with the associated increase in the production of F-actin providing additional anchoring points for scaffolding proteins. Interestingly, one of the mechanisms for increasing the production of F-actin and stabilization of a synapse is enhanced AMPA receptor expression (Matus, 2000). An alternative mechanism for stabilizing a synapse has recently been proposed in a modeling study by Shouval (2005), based on the clustering of interacting receptors within the PSD. Under the hypothesis that receptor clusters can modify the exocytic/endocytic rate of individual receptors, it is shown how receptor clusters can form metastable states that significantly increase the stability of a synapse.

\section{Intrinsic and extrinsic noise}

In this paper, we represented AMPA receptor trafficking in terms of a system of kinetic equations describing the temporal variation in receptor concentrations. These concentrations determine the mean receptor number across a population of synapses. To be a good description of a single synapse, the number of receptors within the synapse has to be sufficiently large; otherwise, random fluctuations about the mean receptor number can become significant. (Typically the size of fluctuations varies as $1 / \sqrt{ } N$, where $N$ is the number of receptors.) One way to determine both the mean and variance of the receptor number is to replace the kinetic equations by a corresponding master equation (Van Kampen, 1992), which describes the temporal evolution of the probability distribution for the receptors within the PSD and ESM. For fixed values of the various trafficking parameters, the resulting fluctuations reflect the inherent stochasticity or "intrinsic noise" of receptor trafficking. However, there are additional sources of fluctuations associated with the underlying biochemical processes that regulate the trafficking parameters, and these represent forms of "extrinsic noise." Elsewhere, we hope to investigate the relative contributions of intrinsic and extrinsic noise to AMPA receptor trafficking within the postsynaptic membrane along analogous lines to a recent study of gene expression (Swain et al., 2002).

\section{References}

Abarbanel HDI, Huerta R, Rabinovich MI (2002) Dynamical model of long-term synaptic plasticity. Proc Natl Acad Sci USA 99:10132-10137.

Adesnik H, Nicoll RA, England PM (2005) Photoinactivation of native AMPA receptors reveals their real-time trafficking. Neuron 48:977-985.

Ashby MC, Maier SR, Nishimune A, Henley JM (2006) Lateral diffusion drives constitutive exchange of AMPA receptors at dendritic spines and is regulated by spine morphology. J Neurosci 26:7046-7055.

Banke TG, Bowie D, Lee H, Huganir RL, Schousboe A, Traynelis SF (2000) Control of GluR1 AMPA receptor function by cAMP-dependent protein kinase. J Neurosci 20:89-102.
Beattie EC, Carroll RC, Yu X, Morishita W, Yasuda H, von Zastrow M, Malenka RC (2000) Regulation of AMPA receptor endocytosis by a signaling mechanism shared with LTD. Nat Neurosci 3:1291-1300.

Benke TA, Luthi A, Isaac JT, Collingridge GL (1998) Modulation of AMPA receptor unitary conductance by synaptic activity. Nature 393:793-797.

Blanpied TA, Scott DB, Ehlers MD (2002) Dynamics and regulation of clathrin coats at specialized endocytic zones of dendrites and spines. Neuron 36:435-449.

Bliss TVP, Collingridge GL (1993) A synaptic model of memory: long-term potentiation in the hippocampus. Nature 361:31-39.

Bliss TVP, Lomo T (1973) Long-lasting potentiation of synaptic transmission in the dentate area of the anaesthetized rabbit following stimulation of the perforant path. J Physiol (Lond) 232:331-356.

Borgdorff AJ, Choquet D (2002) Regulation of AMPA receptor lateral movements. Nature 417:649-653.

Bredt DS, Nicoll RA (2003) AMPA receptor trafficking at excitatory synapses. Neuron 40:361-379.

Carroll RC, Lissin DV, von Zastrow M, Nicoll RA, Malenka RC (1999a) Rapid redistribution of glutamate receptors contributes to long-term depression in hippocampal cultures. Nat Neurosci 2:454-460.

Carroll RC, Beattie EC, Xia H, Luscher C, Altschuler Y, Nicoll RA, Malenka RC, von Zastrow M (1999b) Dynamin-dependent endocytosis of ionotropic glutamate receptors. Proc Natl Acad Sci USA 96:14112-14117.

Castellani GC, Quinlan EM, Cooper LN, Shouval HZ (2001) A biophysical model of bidirectional plasticity: dependence on AMPA and NMDA receptors. Proc Natl Acad Sci USA 98:12772-12777.

Chen L, Chetkovich DM, Petralia RS, Sweeney NT, Kawasaki Y, Wenthold RJ, Bredt DS, Nicoll RA (2000) Stargazin regulates synaptic targeting of AMPA receptors by two distinct mechanisms. Nature 408:936-943.

Choquet D, Triller A (2003) The role of receptor diffusion in the organization of the postsynaptic membrane. Nat Rev Neurosci 4:251-265.

Chung HJ, Xia J, Scannevin RH, Zhang X, Huganir RL (2000) Phosphorylation of the AMPA receptor subunit GluR2 differentially regulates its interaction with PDZ domain-containing proteins. J Neurosci 20:7258-7267.

Colledge M, Snyder EM, Crozier RA, Soderling JA, Jin Y, Langeberg LK, Lu H, Bear MF, Scott JD (2003) Ubiquitination regulates PSD-95 degradation and AMPA receptor surface expression. Neuron 3:595-607.

Collingridge GL, Isaac JTR, Wang YT (2004) Receptor trafficking and synaptic plasticity. Nat Rev Neurosci 5:952-962.

Cottrell JR, Dube GR, Egles C, Liu G (2000) Distribution, density, and clustering of functional glutamate receptors before and after synaptogenesis in hippocampal neurons. J Neurophysiol 84:1573-1587.

Dudek SM, Bear MF (1992) Homosynaptic long-term depression in area CA1 of hippocampus and effects of $N$-methyl-D-aspartate receptor blockade. Proc Natl Acad Sci USA 89:4363-4367.

Dudek SM, Bear MF (1993) Bidirectional long-term modification of synaptic effectiveness in the adult and immature hippocampus. J Neurosci 13:2910-2918.

Ehlers MD (2000) Reinsertion or degradation of AMPA receptors determined by activity-dependent endocytic sorting. Neuron 28:511-525.

El-Husseini AE, Schnell E, Chetkovich DM, Nicoll RA, Bredt DS (2000) PSD-95 involvement in maturation of excitatory synapses. Science 290:1364-1368.

El-Husseini AE, Schnell E, Dakoji S, Sweeney N, Zhou Q, Prange O, GauthierCampbell C, Aguilera-Moreno A, Nicoll RA, Bredt DS (2002) Synaptic strength regulated by palmitate cycling on PSD-95. Cell 108:849-863.

Franks KM, Sejnowski TJ (2002) Complexity of calcium signaling in synaptic spines. BioEssays 24:1130-1144.

Groc L, Heine M, Cognet L, Brickley K, Stephenson FA, Lounis B, Choquet D (2004) Differential activity-dependent regulation of the lateral mobilities of AMPA and NMDA receptors. Nat Neurosci 7:695-696.

Hanse E, Gustafsson B (1992) Postsynaptic, but not presynaptic, activity controls the early time course of long-term potentiation in the dentate gyrus. J Neurosci 12:3226-3240.

Hayashi Y, Shi SH, Esteban JA, Piccini A, Poncer JC, Malinow R (2000) Driving AMPA receptors into synapses by LTP and CaMKII: requirement for GluR1 and PDZ domain interaction. Science 287:2262-2267.

Hayer A, Bhalla US (2005) Molecular switches at the synapse emerge from receptor and kinase traffic. PLoS Comput Biol 1:137-154.

Holcman D, Schuss Z (2004) Escape through a small opening: receptor trafficking in a synaptic membrane. J Stat Phys 117:976-1014.

Holmes WR, Grover LM (2006) Quantifying the magnitude of changes in 
synaptic level parameters with long-term potentiation. J Neurophysiol 96:1478-1491.

Inoue A, Okabe S (2003) The dynamic organization of postsynaptic proteins: translocating molecules regulate synaptic function. Curr Opin Neurobiol 13:332-340.

Karmarkar UR, Buonomano DV (2002) A model of spike-timing dependent plasticity: one or two coincidence detectors? J Neurophysiol 88:507-513.

Kasai H, Matsuzaki M, Noguchi J, Yasumatsu N, Nakahara H (2003) Structure-stability-function relationships of dendritic spines. Trends Neurosci 26:360-368.

Kennedy MJ, Ehlers M (2006) Organelles and trafficking machinery for postsynaptic plasticity. Annu Rev Neurosci 29:325-362.

Kim CH, Chung HJ, Lee HK, Huganir RL (2001) Interaction of AMPA receptor subunit GluR2/3 with PDZ domains regulates hippocampal longterm depression. Proc Natl Acad Sci USA 98:11725-11730.

Kitajima T, Hara K (2000) A generalized Hebbian rule for activitydependent synaptic modifications. Neural Netw 13:445-454.

Lamprecht R, LeDoux J (2004) Structural plasticity and memory. Nat Rev Neurosci 5:45-54.

Lauffenburger DA, Linderman JJ (1993) . Receptors: models for binding, trafficking and signaling. New York: Oxford UP.

Lee HK, Kameyama K, Huganir RL, Bear MF (1998) NMDA induces longterm synaptic depression and dephosphorylation of the GluR1 subunit of AMPA receptors in hippocampus. Neuron 21:1151-1162.

Lee HK, Barbarosie M, Kameyama K, Bear MF, Huganir RL (2000) Regulation of distinct AMPA receptor phosphorylation sites during bidirectional synaptic plasticity. Nature 405:955-959.

Lee HK, Takamiya K, Han JS, Man H, Kim CH, Rumbaugh, G.,Yu S, Ding L, He C, Petralia RS, Wenthold RJ, Gallagher M, Huganir RL (2003) Phosphorylation of the AMPA receptor GluR1 subunit is required for synaptic plasticity and retention of spatial memory. Cell 112:631-643.

Lin JW, Ju W, Foster K, Lee SH, Ahmadian G, Wyszynski M, Wang YT, Sheng M (2000) Distinct molecular mechanisms and divergent endocytotic pathways of AMPA receptor internalization. Nat Neurosci 3:1282-1290.

Lisman JE (2003) Long-term potentiation: outstanding questions and attempted synthesis. Philos Trans R Soc Lond B Biol Sci 358:829-842.

Lisman JE, Zhabotinsky AM (2001) A model of synaptic memory: a CaMKII/PP1 switch that potentiates transmission by organizing an AMPA receptor anchoring assembly. Neuron 31:191-201.

Lisman JE, Schulman H, Cline H (2002) The molecular basis of CaMKII function in synaptic and behavioural memory. Nat Rev Neurosci 3:175-190.

Lu W, Ziff EB (2005) PICK1 interacts with ABP/GRIP to regulate AMPA receptor trafficking. Neuron 47:407-421.

Luscher C, Xia H, Beattie EC, Carroll RC, von Zastrow M, Malenka RC, Nicoll RA (1999) Role of AMPA receptor cycling in synaptic transmission and plasticity. Neuron 24:649-658.

Malenka RC, Bear MF (2004) LTP and LTD: an embarrassment of riches. Neuron 44:5-21.

Malenka RC, Nicoll RA (1999) Long-term potentiation-a decade of progress? Science 285:1870-1874.

Malinow R (2003) AMPA receptor trafficking and long-term potentiation. Philos Trans R Soc Lond B Biol Sci 358:707-714.

Malinow R, Malenka RC (2002) AMPA receptor trafficking and synaptic plasticity. Annu Rev Neurosci 25:103-126.

Man HY, Lin JW, Ju WH, Ahmadian G, Liu L, Becker LE, Sheng M, Wang YT (2000) Regulation of AMPA receptor-mediated synaptic transmission by clathrin-dependent receptor internalization. Neuron 25:649-662.

Matsuda S, Launey T, Mikawa S, Hirai H (2000) Disruption of AMPA receptor GluR2 clusters following long-term depression nduction in cerebellar Purkinje neurons. EMBO J 19:2765-2774.

Matus A (2000) Actin-based plasticity in dendritic spines. Science 290:754-758.

Mauceri D, Cattabeni F, Di Luca M, Gardoni F (2004) Calcium/calmodulindependent protein kinase II phosphorylation drives synapse-associated protein 97 into spines. J Biol Chem 279:23813-23821.

McCormack SG, Stornetta RL, Zhu JJ (2006) Synaptic AMPA receptor exchange maintains bidirectional plasticity. Neuron 50:75-88.

Nusser Z, Lujan R, Laube L, Roberts JDB, Molnar E, Somogyi P (1998) Cell type and pathway dependence of synaptic AMPA receptor number and variability in the hippocampus. Neuron 21:545-549.
O'Connor DH, Wittenberg GM, Wang SS-H (2005) Graded bidirectional synaptic plasticity is composed of switch-like unitary events. Proc Natl Acad Sci USA 102:9679-9684.

Okabe S, Kim H-D, Miwa A, Kuriu T, Okado H (1999) Continual remodeling of postsynaptic density and its regulation by synaptic activity. Nat Neurosci 9:804-811.

Park M, Penick EC, Edwards JG, Kauer JA, Ehlers MD (2004) Recycling endosomes supply AMPA receptors for LTP. Science 305:1972-1975.

Passafaro M, Piech V, Sheng M (2001) Subunit-specific temporal and spatial patterns of AMPA receptor exocytosis in hippocampal neurons. Nat Neurosci 4:917-926.

Perez JL, Khatri L, Chang C, Srivastava S, Osten P, Ziff EB (2001) PICK1 targets activated protein kinase $\mathrm{C} \alpha$ to AMPA receptor clusters in spines of hippocampal neurons and reduces surface levels of the AMPA-type glutamate receptor subunit 2. J Neurosci 21:5417-5428.

Petersen CCH, Malenka RC, Nicoll RA, Hopfield JJ (1998) All-or-none potentiation at CA3-CA1 synapses. Proc Natl Acad Sci USA 95:4732-4737.

Poncer JC, Esteban JA, Malinow R (2002) Multiple mechanisms for the potentiation of AMPA receptor mediated transmission by $\alpha-\mathrm{Ca}^{2+}$ / calmodulin-dependent protein kinase II. J Neurosci 22:4406-4411.

Rubin JE, Gerkin RC, Bi G-Q, Chow CC (2005) Calcium time course as a signal for spike-timing dependent plasticity. J Neurophysiol 93:2600-2613.

Schnell E, Sizemore M, Karimzadegan S, Chen L, Bredt DS, Nicoll RA (2002) Direct interactions between PSD-95 and stargazin control synaptic AMPA receptor number. Proc Natl Acad Sci USA 99:13902-13907.

Sheng M, Kim MJ (2002) Postsynaptic signaling and plasticity mechanisms. Science 298:776-780.

Shi S, Hayashi Y, Esteban JA, Malinow R (2001) Subunit-specific rules governing AMPA receptor trafficking to synapses in hippocampal pyramidal neurons. Cell 105:331-343.

Shouval HZ, Bear MF, Cooper LN (2002a) A unified model of NMDA receptor-dependent bidirectional synaptic plasticity. Proc Natl Acad Sci USA 99:10831-10836.

Shouval HZ, Castellani GC, Blais BS, Yeung LC, Cooper LN (2002b) Converging evidence for a simplified biophysical model of synaptic plasticity. Biol Cybern 87:383-391.

Shouval HZ (2005) Clusters of interacting receptors can stabilize synaptic efficacies. Proc Natl Acad Sci USA 102:14440-14445.

Song I, Huganir RL (2002) Regulation of AMPA receptors during synaptic plasticity. Trends Neurosci 25:578-588.

Sorra KE, Harris KM (2000) Overview on the structure, composition, function, development, and plasticity of hippocampal dendritic spines. Hippocampus 10:501-511.

Steinberg JP, Takamiya K, Shen Y, Xia J, Rubio ME, Yu S, Jin W, Thomas GM, Linden DJ, Huganir RL (2006) Targeted in vivo mutations of the AMPA receptor subunit GluR2 and its interactin protein PICK1 eliminate cerebellar long-term depression. Neuron 49:845-860.

Swain PS, Elowitz MB, Siggia ED (2002) Intrinsic and extrinsic contributions to stochasticity in gene expression. Proc Natl Acad Sci USA 99:12795-12800.

Tanaka J-I, Matsuzaki M, Tarusawa E, Momiyama A, Molnar E, Kasai H, Shigemoto R (2005) Number and density of AMPA receptors in single synapses in immature cerebellum. J Neurosci 25:799-807.

Tomita S, Stein V, Stocker TJ, Nicoll RA, Bredt DS (2005) Bidirectional synaptic plasticity regulated by phosphorylation of stargazin-like TARPs. Neuron 45:269-277.

Triller A, Choquet D (2003) Synaptic structure and diffusion dynamics of synaptic receptors. Biol Cell 95:465-476.

Triller A, Choquet D (2005) Surface trafficking of receptors between synaptic and extrasynaptic membranes. Trends Neurosci 28:133-139.

Van Kampen NG (1992) Stochastic processes in physics and chemistry. Amsterdam: North-Holland.

Winder DG, Sweatt JD (2001) Roles of serine/threonine phosphatases in hippocampal synaptic plasticity. Nat Rev Neurosci 2:461-474.

Wu H, Nash JE, Zamorano P, Garner CC (2002) Interaction of SAP97 with minus-end-directed actin motor myosin VI. Implications for AMPA receptor trafficking. J Biol Chem 277:30928-30934.

Zhabotinsky AM (2000) Bistability in the $\mathrm{Ca}^{2+}$ calmodulin-dependent protein kinase-phosphatase system. Biophys J 79:2211-2221. 